\title{
A study on the heavy rainfall event around Kedarnath area (Uttarakhand) on 16 June 2013
}

\author{
M S Shekhar ${ }^{1, *}$, S PATtanayaK ${ }^{2}$, U C MOHANTY ${ }^{2}$, \\ S PAUL ${ }^{3}$ and M SRAVANA KUMAR ${ }^{1}$ \\ ${ }^{1}$ Snow 85 Avalanche Study Establishment, Research 83 Development Centre, Him Parisar, Sector 37A, \\ Chandigarh 160 036, India. \\ ${ }^{2}$ School of Earth, Ocean and Climate Sciences, Indian Institute of Technology, Bhubaneswar, \\ Toshali Bhavan, Satya Nagar, Bhubaneswar 751 007, India. \\ ${ }^{3}$ Meteorological Office, Sector-39, Chandigarh 160 022, India. \\ ${ }^{*}$ Corresponding author. e-mail: sudhanshu@sase.drdo.in
}

The heavy rainfall event during 14-17 June 2013 in Uttarakhand and more specifically, its occurrence around the Kedarnath region on 16 June 2013 with devastating floods and massive landslides ruined thousands of lives and properties. Increasing levels of water in two main rivers of the State, namely Alaknanda and Mandakini, resulted in the collapse of bridges, damaging and washing away of property worth many crores. In the present study, the advanced research version of the Weather Research and Forecasting (WRF) system (hereafter used as WRF model) is used to simulate this heavy rainfall event. The synoptic analysis at different locations such as Rudraprayag, Uttarkashi, Chamoli, Pauri, Tehri, Dehradun and adjoining districts suggested that the rainfall is about $200 \%$ more than normal. The rainfall associated with this event is well captured with the model simulation. The rainfall simulated by WRF model is in the range of 320-400 mm over Kedarnath during the actual occurrence of the event, which is in reasonably good agreement with the observed value of rainfall $(325 \mathrm{~mm})$ collected by Wadia Institute of Himalayan Geology.

\section{Introduction}

The complex orography in the foothills of the Himalayas and more specifically in the northern states of India significantly influences the extreme events like heavy to very heavy rainfall/snowfall, avalanches, cloudbursts, flash floods, landslides, etc. The low level convergence of south-easterlies and north-westerlies along with the complex terrain of foothills coupled with vertical shear of wind and orographic uplifting lead to short-lived intense convective precipitation. The mountainous regions of Uttarakhand are frequented by many weatherand terrain-related hazards due to its intricate geospatial location, leading to significant loss of lives and damage to the property.
During 14-17 June 2013, Uttarakhand and its adjoining areas received heavy rainfall associated with landslides that caused a huge damage and ceased many lives. Also, the occurrence of such high impact events in Uttarakhand during monsoon season are not uncommon. Uttarakhand has experienced many such heavy rainfall events in the past, mainly during the months of July and August. In September 1970, heavy rainfall and landslides claimed lives of 223 people in Uttarakhand. Similarly, on 16 July 2001, 14 villages were affected, 27 people lost their lives in this event, along with damage to 154 houses. More than 43 hectares of agricultural land was also washed away and $11 \mathrm{~km}$ stretch of Rudraprayag-Kedarnath road got severely damaged. On 6 August 2010, Leh was

Keywords. Uttarakhand; heavy rainfall; floods; mesoscale model. 
down-poured with a cloudburst event and a detailed study was carried out by Ashrit (2010), Sravan et al. (2012) and Thayyen et al. (2013). However, the June 2013 heavy rainfall event that occured in the holy pilgrim area Kedarnath ceased thousands of lives and caused catastrophic damage due to landslides, debris flow and extensive flooding. Also, this extreme rainfall event occurred for the first time in the month of June and extended the entire Uttarakhand. Because of the lack of vegetation and higher friction over terrain slopes, the rainwater along with the rocks and mud gushed through the populated areas and caused heavy loss of human life and property. Joseph et al. (2014) studied the basis of heavy rainfall events of Uttarakhand in the perspective of large scale monsoon and suggested that the monsoonal low pressure system enhances the low-level convergence with excessive moisture interacting with strong upper-level divergence produced through mid-latitude westerly trough that augmented the monsoonal heavy rainfall in the orographic region. The study also examines the extended range prediction of the event through coupled general circulation model CFSv2 and suggested that CFS model could predict the event 1012 days in advance, though the mid-latitude influence is not captured. Singh et al. (2014) examined the dynamics of the June 2013 heavy rainfall event in the context of historical and pre-industrial climate and suggested that the early arrival of monsoon brought heavy rainfall in the mountain region where snow cover typically melts prior to the onset of monsoon. The study also claims that the impact of anthropogenic forcing increased the likelihood of such an event. Srinivasan (2013) hypothesized that a landslide caused by the heavy rainfall event might have blocked the Mandakini River which originated from the Chorabari Glacier of the Himalayas and the dammed water behind the landslide might have flushed in the early morning of 17 June. Dobhal et al. (2013) concluded that the heavy rainfall during 15-17 June 2013, along with the melting snow in the surrounding Chorabari Lake, washed off the banks of Mandakini River, causing massive devastation. The floods triggered landslides as a catalyst to damage structures, killing the trapped people and caused vulnerability to properties. The present study on the simulation of a heavy rainfall event in Uttarakhand and more precisely surrounding Kedarnath is a more concise numerical approach to predict the unprecedented heavy rainfall with a few presentations of synoptic features, though a few synoptic studies have already been carried out by Dobhal et al. (2013) and Dube et al. (2013).

Uttarakhand witnessed an intense heavy rainfall event in the afternoon/wee hours of 16 June 2013, which resulted in heavy loss of lives and property in the districts of Rudraprayag, Uttarkashi, Chamoli, Pauri and Tehri. The holy shrine of Kedarnath was the scene of maximum destruction. As a first step towards the synoptic analysis of the event along with the prediction of such extreme events numerically, this paper makes an effort to simulate the event on 16 June 2013, so as to capture the quantitative precipitation associated with this event.

The methodology and data used is provided in section 2. The results and discussion describing the synoptic features as well as the model simulated results are presented in section 3, followed by conclusions in section 4 .

\section{Data and methodology}

There is no adequate technique to predict the heavy rainfall event in the complex mountainous region due to coarse resolution of the meteorological data network. Numerical weather prediction models often fail to simulate and predict these types of events due to the limitations of the upper atmospheric profile data as well as a high resolution data network over the region. Remote sensing data over the regions also need to be of very high temporal and spatial resolution to capture the characteristics of the event. As a first step towards the prediction of such extreme events, this study makes an effort to simulate the event on 16 June 2013 by using the Weather Research and Forecasting (WRF) model, so as to capture the precipitation associated with this localized mesoscale phenomenon. Snow and Avalanche Study Establishment (SASE), Chandigarh, gives mountain weather forecast 6 days in advance by using WRF model covering the snowbound mountainous areas of western and central Himalaya with a grid resolution of $9 \times 9 \mathrm{~km}$. The SASE has established an Automatic Weather Station (AWS) just near to the Kedarnath temple so as to monitor various atmospheric phenomena and give weather and avalanche forecast to the users, mainly Army and Indo-Tibetan Border Police (ITBP) deployed in those areas. However, due to heavy rainfall, the AWS was badly affected and stopped disseminating data after $2000 \mathrm{hrs}$ IST on 16 June 2013. There was no observational record of precipitation over the study region, i.e., over Kedarnath except that of Wadia Institute of Himalayan Geology. The AWS of Snow \& Avalanche Study Establishment which had been installed just at the back side of the Kedarnath temple stopped dissemination of data after $2000 \mathrm{hrs} \mathrm{IST}$ on 16 June 2013. Due to nonavailability of precipitation sensor at the station, the data with regard to observed precipitation in the area during that period could not be recorded. However, the precipitation observation from the Meteorological 
Department of Chandigarh gives a district-wise rainfall distribution.

In this study, the high resolution non-hydrostatic Advanced Research WRF (ARW) mesoscale model (version 3.2.1) developed at National Centre for Atmospheric Research (NCAR) is used to simulate the heavy rainfall on 16 June 2013. It is a fully compressible primitive equation model and versatile for both research and operational purposes. In the present study, a single domain with resolution of $3 \mathrm{~km}$, keeping Kedarnath and its adjoining areas as the center is used. The configuration used to run the model is depicted in table 1 . The performance of mesoscale models depends on the quality, consistency and representativeness of initial and lateral boundary conditions. Mohanty et al. (2010) examined the performances of GFS, FNL, and NCMRWF global analyses/forecast products as initial and boundary conditions (IBCs) to the WRF-ARW model in the simulation tropical cyclones over Bay of Bengal and suggested the superior performance of FNL data. The FNL data is the final analysis that comprises all the late arriving conventional and satellite data at National Centre for Environmental Prediction (NCEP). The details of the FNL data can be found in Kanamitsu (1989). So, it has been hypothesized that the use of FNL data will improve the prediction of heavy rainfall event and the same is used in this study. Thus, the initial and lateral boundary conditions are obtained from $(\mathrm{FNL})\left(1^{\circ} \times 1^{\circ}\right)$ data. The model is integrated with the initial condition of 00 UTC 14 June 2013 for a period of $96 \mathrm{hrs}$. The precipitation as simulated by the model has been studied. A similar study has also been carried out by Dube et al. (2013) by using the Global Forecast System (T574) and National Center for Medium Range Weather Forecasting (NCMRWF) Unified Model (NCUM) at $22 \mathrm{~km}$ and $25 \mathrm{~km}$ resolution respectively. A comparison of the forecasts made by the two deterministic models runat NCMRWF and their respective skills in predicting high rainfall event associated with this event is presented.

\section{Results and discussion}

The synoptic features as well as numerical simulation results of the Kedarnath heavy rainfall event are presented in this section.

\subsection{Synoptic features of the event}

The heavy rainfall event in mid-June 2013, centered on the north Indian state of Uttarakhand caused devastating flood and landslides which is the worst natural disaster since the 2004 tsunami over south peninsular region of India. Although some parts of Himachal Pradesh, Haryana, Delhi and Uttar Pradesh in India experienced floods and some regions of western Nepal and western Tibet experienced heavy to very heavy rainfall, $95 \%$ of the casualties occurred in Uttarakhand. The state of Uttarakhand was severely affected by floods and landslides following the torrential rainfall in the Kedarnath region ( $30.73^{\circ}$ lat. and $79.1^{\circ}$ long.) from 14 to 17 June 2013. Incidents of heavy rainfall and landslides across the state have led to the death of more than 5000 people in the region. Increasing levels of water in two main rivers of the State, namely Alaknanda and Mandakini, also resulted in the collapse of bridges, damaging and washing away of property worth many crores as per the initial estimate. A few more incidents of heavy rainfall were also reported in the districts of Pauri Garhwal on 24 June. According to the initial information received from different sources, some 30 shops, 40-50 livestock and 10 houses were lost in the Paittani village of Pauri District. There was a reasonably large reservoir, known as Chorabari Lake or Gandhi Sarovar, situated

Table 1. Configuration of WRF model used to simulate the Kedarnath heavy rainfall event.

\begin{tabular}{ll}
\hline Characteristic feature & \multicolumn{1}{c}{ WRF model specification } \\
\hline Horizontal resolution & $3 \mathrm{~km}$ \\
Horizontal grid & Arakawa C grid staggering \\
Acoustic and gravity wave models & Third order Runge-Kutta scheme \\
Cloud micro physics & WRF single moment class 6 Graupel scheme (WSM6) \\
Cumulus convection parameterization scheme & New Kain-Fritsch scheme (KF2) \\
Planetary boundary scheme & Yonsei University scheme (YSU) \\
Long wave radiation & Rapid radiative transfer model (RRTM) \\
Short wave radiation & Dudhia scheme \\
Map projection & Lambert conformal \\
Time integration scheme & Leapfrog scheme with time-splitting technique \\
Soil model & Multi-layer soil temperature model \\
Topography & USGS 30" data \\
No. of vertical levels & 38 levels \\
\hline
\end{tabular}


upstream of the Kedarnath temple which burst on 17 June. This was accompanied by heavy rainfall in the same area, which resulted in huge flow of water and release of silt (Dobhal et al. 2013). It filled the temple complex of Kedernath and the surrounding places, burying thousands of pilgrims

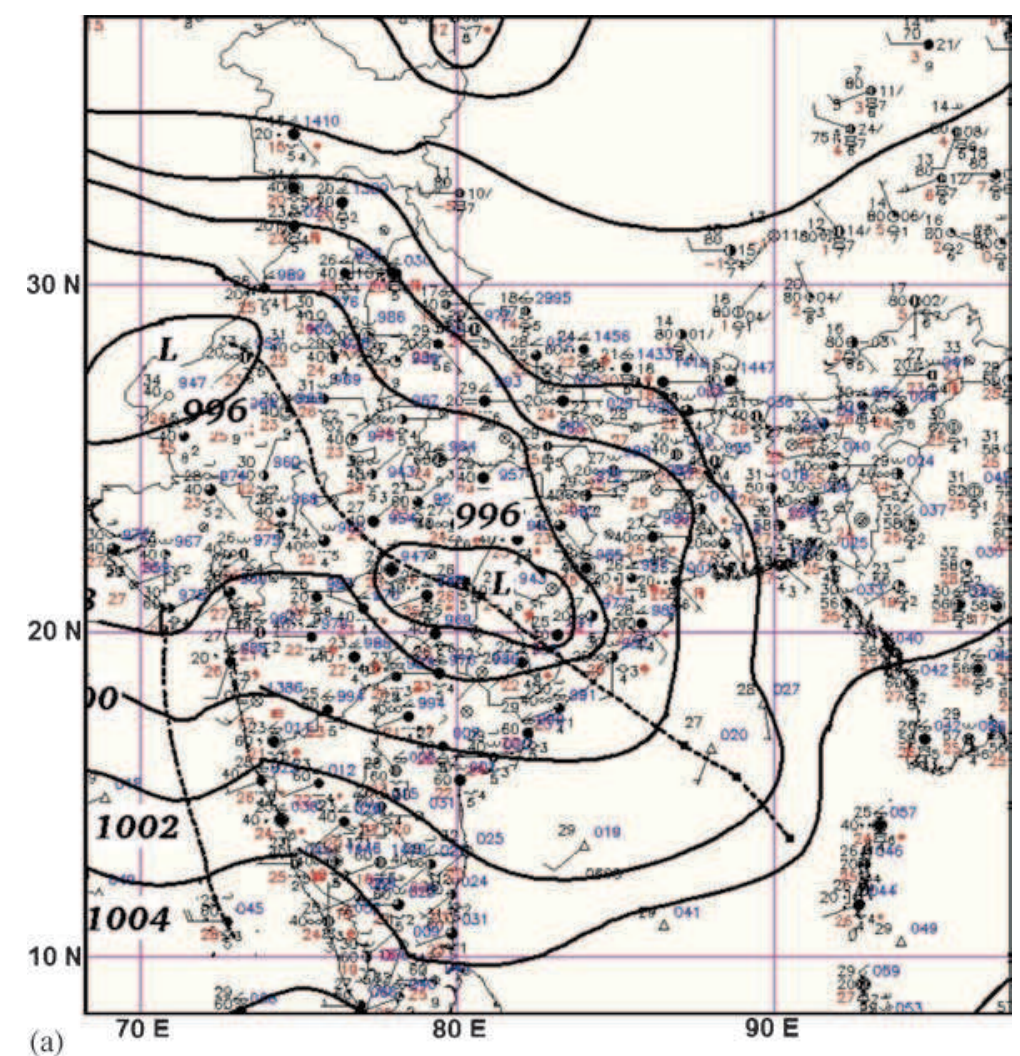

(a)

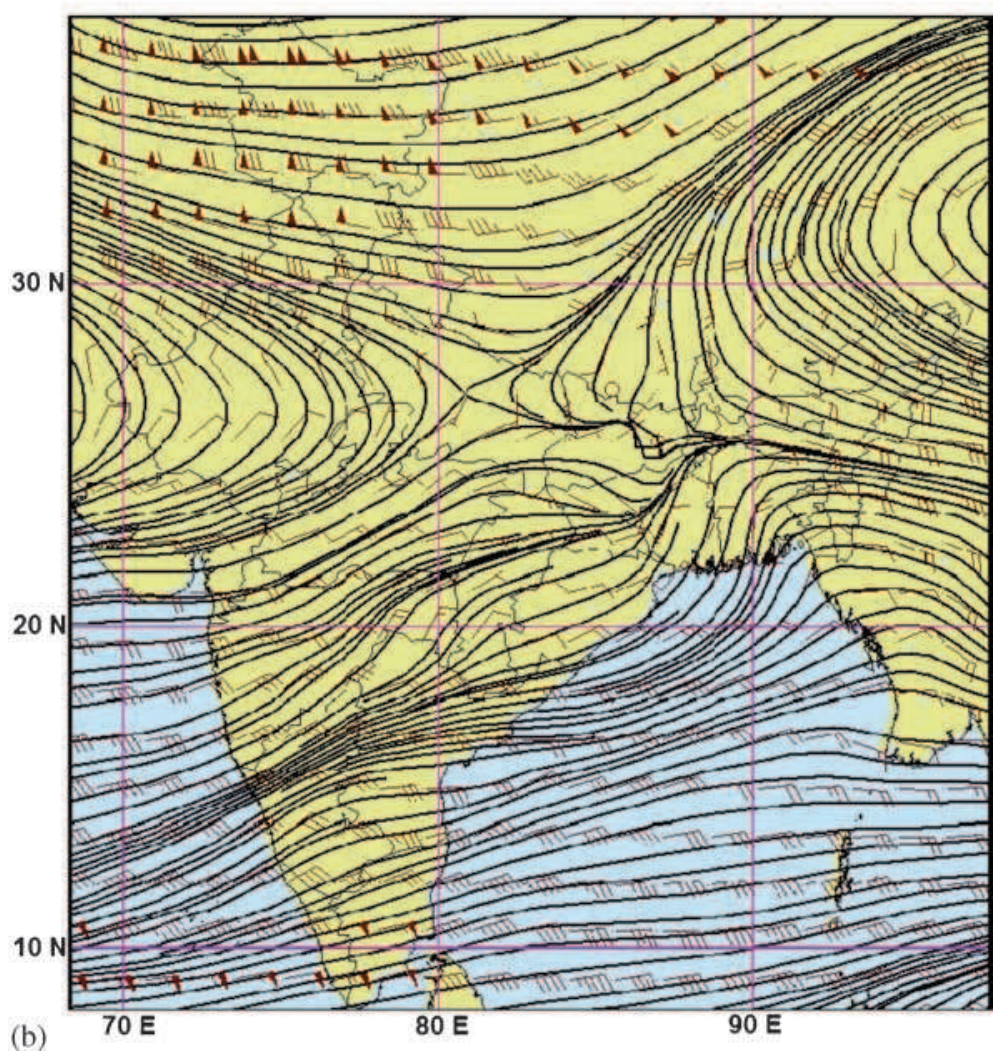

Figure 1. (a) Mean surface pressure at 00 UTC of 15 June 2013 and (b) wind field at 200 hpa at 00 UTC of 15 June 2013. 
and local people. Many roads connecting the pil- In various parts of Uttarakhand around 400 roads grim centers like Kedarnath, Badrinath, Gangotri, were damaged, making communication and transYamunotri and Govindghat have been damaged. portation difficult during this period. This being

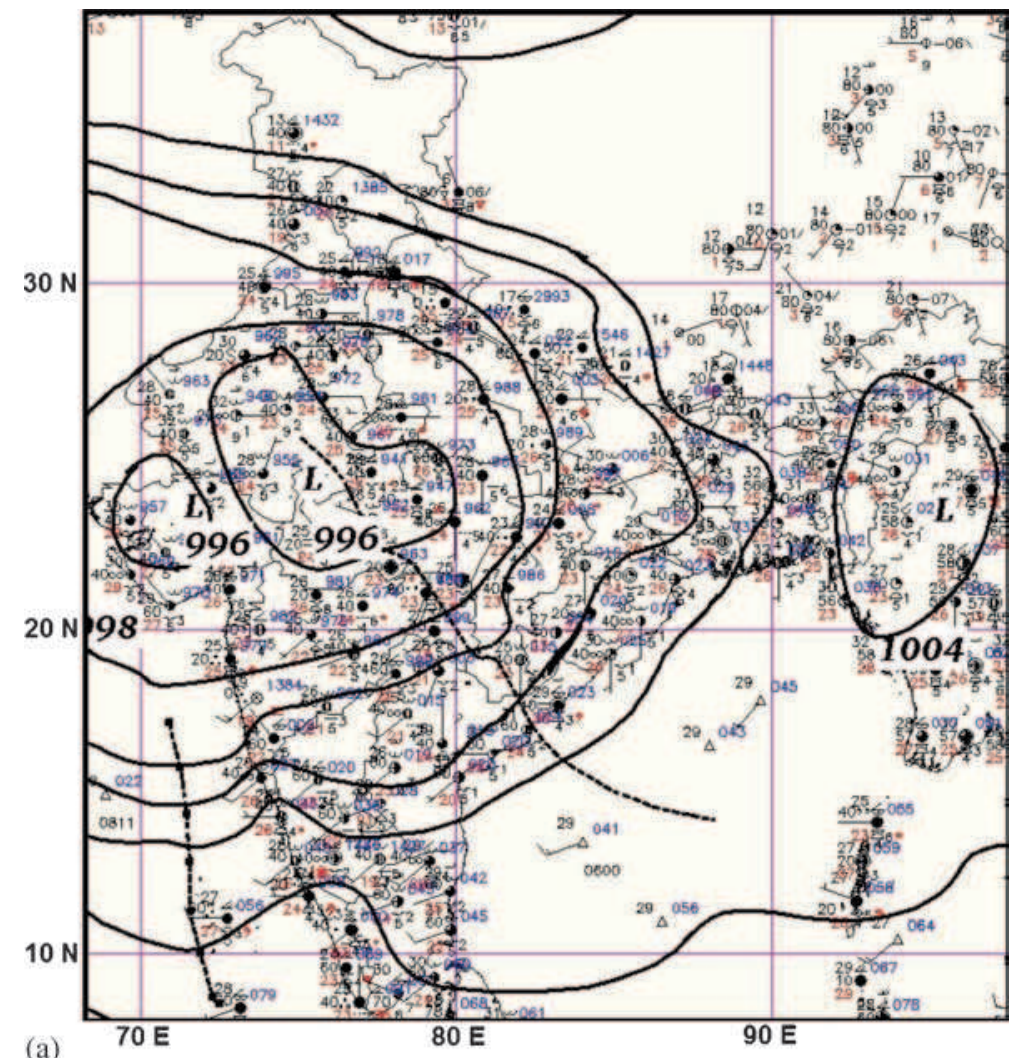

(a)

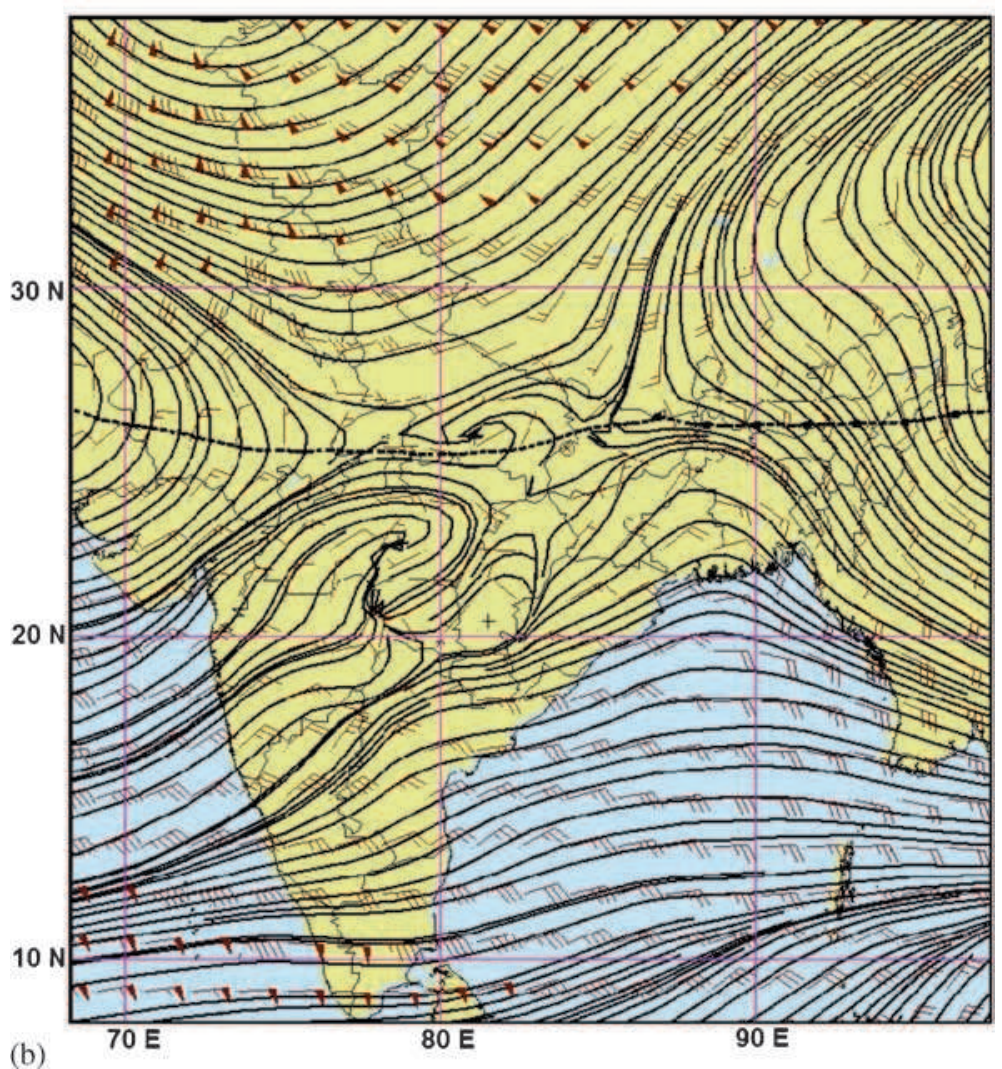

Figure 2. (a) Mean surface pressure at 00 UTC of 16 June 2013 and (b) wind field at 200 hpa at 00 UTC of 16 June 2013. 
the time of pilgrimage: Chardham yatra of Hindus and visit to the holy place of the Sikh community to Govindghat (Himkund Sahib) near Joshimath, there was a huge crowd of pilgrims congregated in these places. As per the newspaper report, over 70,000 pilgrims were stranded at Rudraprayag,

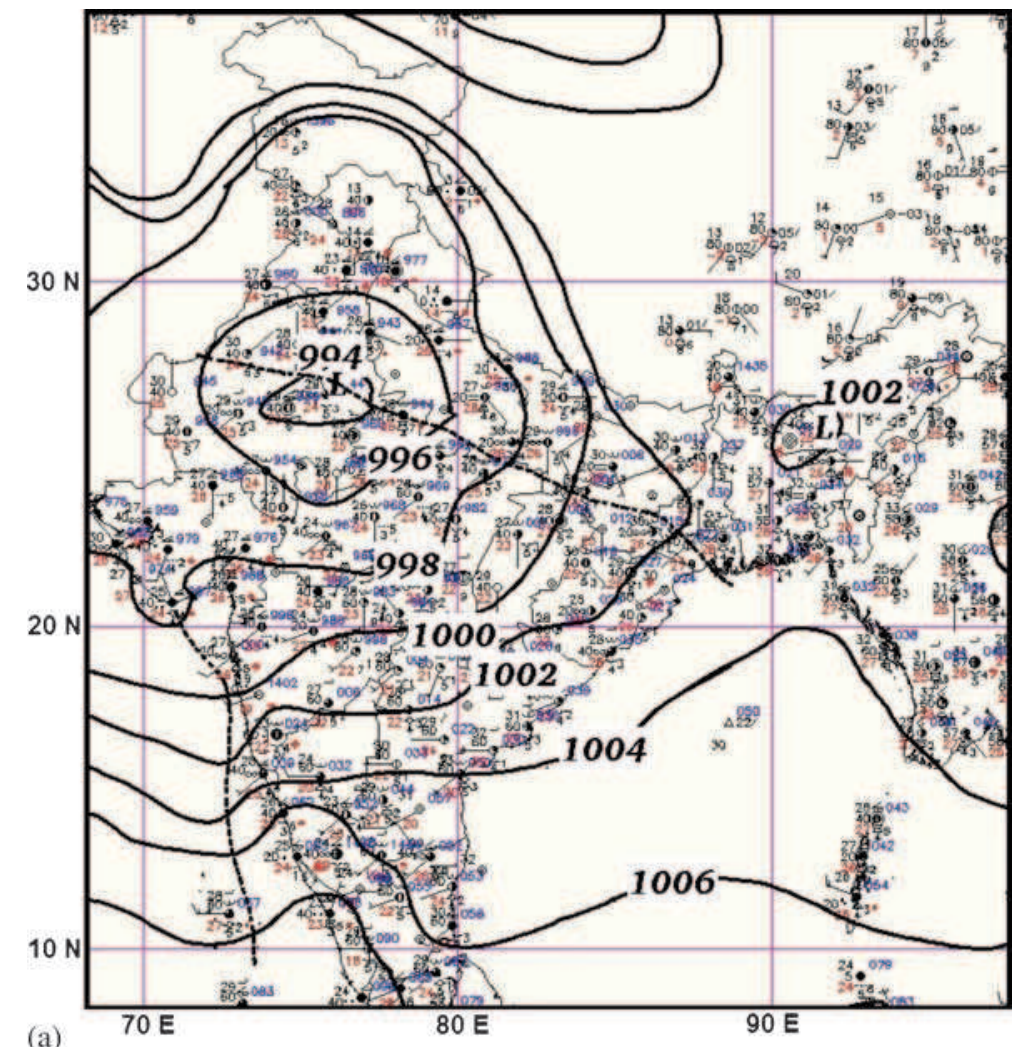

(a)

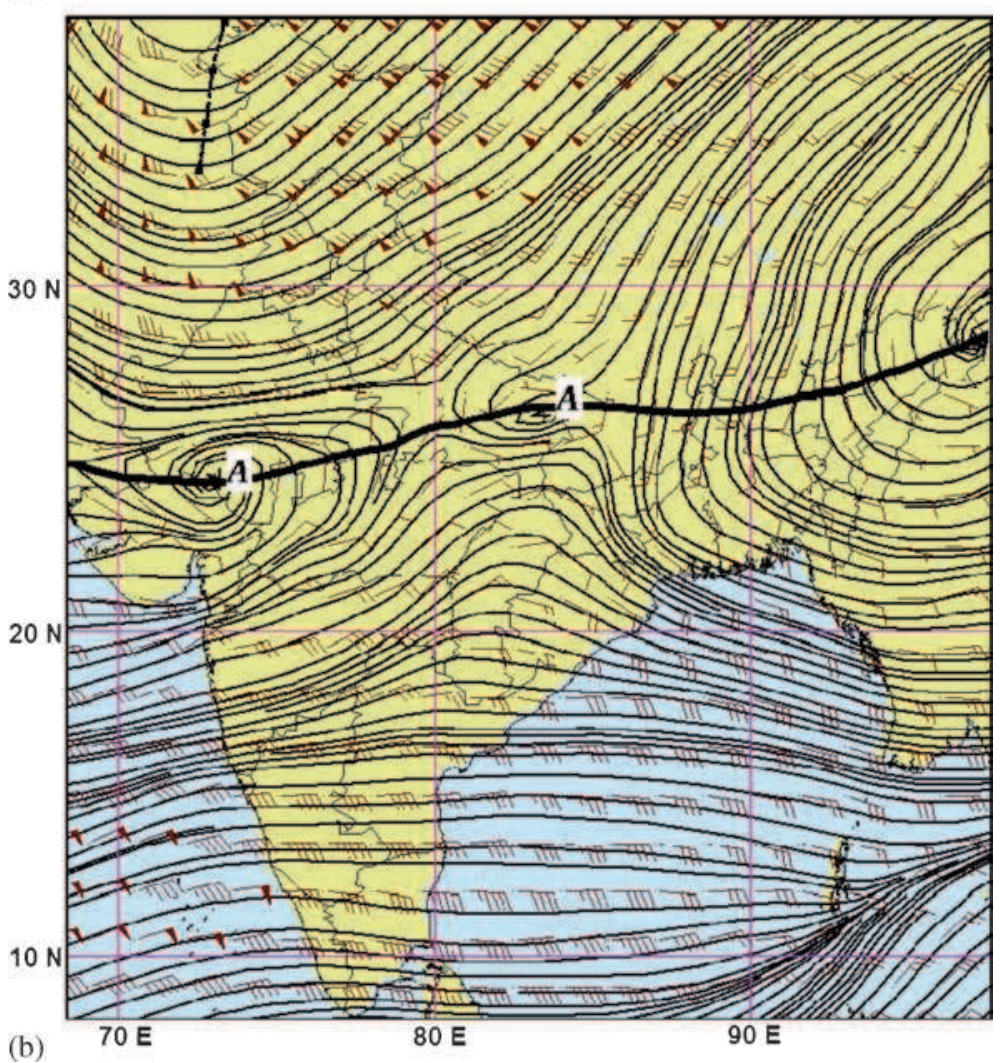

Figure 3. (a) Mean surface pressure at 00 UTC of 17 June 2013 and (b) wind field at 200 hpa at 00 UTC of 17 June 2013. 
Chamoli and Uttarkashi areas - 27,000 pilgrims in Chamoli, 25,000 in Rudraprayag and nearly 9000 in Uttarkashi. Severe problems of accommodation and food were faced during their evacuation by the Indian army. The destruction of bridges and roads left about 100,000 pilgrims and tourists trapped in

Table 2. Synoptic situations recorded at 00 and 12 UTC during 15-17 June 2013 at Dehradun.

\begin{tabular}{|c|c|c|c|c|c|}
\hline Date & $\begin{array}{l}\text { Synoptic hrs } \\
\text { in UTC }\end{array}$ & Cloud particulars & MSLP & P24 & $\begin{array}{l}\text { Wind direction/ } \\
\text { speed (knots) }\end{array}$ \\
\hline \multirow[t]{2}{*}{15 June, 203} & 3 & $\begin{array}{l}\text { Sky obscured with two octa low clouds } \\
\text { Sc and Cb and overcast with medium } \\
\text { cloud of As, base of low between } 600 \text { and } \\
900 \mathrm{M}\end{array}$ & 1003 & 1.4 & WWS/01 \\
\hline & 12 & $\begin{array}{l}\text { Sky obscured with six octa low clouds } \\
\mathrm{Sc}, \mathrm{Cu} \text { and } \mathrm{Cb} \text { and six octa of medium } \\
\text { cloud of As, base of low clouds between } \\
600 \text { and } 900 \mathrm{M}\end{array}$ & 989.9 & 1.6 & CALM \\
\hline \multirow[t]{2}{*}{16 June, 2013} & 3 & $\begin{array}{l}\text { Sky obscured with six octa low clouds } \\
\text { St, Sc and Cb and overcast with medium } \\
\text { cloud of As, base of low clouds between } \\
300 \text { and } 599 \mathrm{M}\end{array}$ & 1001.7 & -1.7 & $\mathrm{NE} / 01$ \\
\hline & 12 & $\begin{array}{l}\text { Sky obscured with seven octa low clouds } \\
\text { St, Sc and Cb and overcast with medium } \\
\text { cloud of As, base of low clouds between } \\
200 \text { and } 299 \mathrm{M}\end{array}$ & 998.2 & -1.6 & NE/01 \\
\hline \multirow[t]{2}{*}{17 June, 2013} & 3 & $\begin{array}{l}\text { Sky obscured with six octa low clouds } \\
\text { St and Sc and overcast with medium } \\
\text { cloud of As, base of low clouds between } \\
300 \text { and } 599 \mathrm{M}\end{array}$ & 997.7 & -3.6 & $\mathrm{NW} / 01$ \\
\hline & 12 & $\begin{array}{l}\text { Sky obscured with six octa low clouds } \\
\text { Sc and overcast with medium cloud of } \\
\text { As, base of low clouds between } \\
600 \text { and } 999 \mathrm{M}\end{array}$ & 993.9 & -3.6 & CALM \\
\hline
\end{tabular}

Table 3. Synoptic situations recorded at 00 and 12 UTC during 15-17 June 2013 at Pant Nagar.

\begin{tabular}{|c|c|c|c|c|c|}
\hline Date & $\begin{array}{l}\text { Synoptic hrs } \\
\text { in UTC }\end{array}$ & Cloud particulars & MSLP & P24 & $\begin{array}{l}\text { Wind direction/ } \\
\text { speed (knots) }\end{array}$ \\
\hline \multirow[t]{2}{*}{15 June, 203} & 3 & $\begin{array}{l}\text { Seven Octa cloud cover with two octa } \\
\text { low clouds Sc and seven octa of medium } \\
\text { cloud of Ac, base of low clouds between } \\
600 \text { and } 999 \mathrm{M}\end{array}$ & - & 0.4 & $\mathrm{E} / 02$ \\
\hline & 12 & $\begin{array}{l}\text { Sky obscured with two octa low clouds St and } \\
\text { overcast with medium cloud As, base of low } \\
\text { clouds between } 300 \text { and } 599 \mathrm{M}\end{array}$ & - & 1.7 & $\mathrm{EEN} / 06$ \\
\hline \multirow[t]{2}{*}{16 June, 2013} & 3 & $\begin{array}{l}\text { Sky obscured with three octa low clouds St and } \\
\text { overcast with medium cloud of As, base of low } \\
\text { clouds between } 300 \text { and } 599 \mathrm{M}\end{array}$ & - & -1 & $\mathrm{E} / 04$ \\
\hline & 12 & $\begin{array}{l}\text { Sky obscured with five octa low clouds St and } \\
\text { Sc and overcast with medium cloud of As, } \\
\text { base of low clouds between } 300 \text { and } 599 \mathrm{M}\end{array}$ & - & -1.7 & EEN/04 \\
\hline \multirow[t]{2}{*}{17 June, 2013} & 3 & $\begin{array}{l}\text { Sky obscured with six octa low clouds St and } \\
\text { Sc and overcast with medium cloud of As, } \\
\text { base of low clouds between } 300 \text { and } 599 \mathrm{M}\end{array}$ & - & - & $\mathrm{E} / 04$ \\
\hline & 12 & $\begin{array}{l}\text { Sky obscured with six octa low clouds Sc } \\
\text { and overcast with medium cloud of As, } \\
\text { base of low clouds between } 300 \text { and } 599 \mathrm{M}\end{array}$ & - & -2.1 & $\mathrm{E} / 08$ \\
\hline
\end{tabular}


the valleys that lead to the four Hindu Chota Char Dham pilgrimage sites.

The synoptic features of the event from its initiation to decay are presented through mean sea level pressure and wind field.

On 15 June 2013, the western disturbance (WD) as an upper air system laid over north Pakistan and adjoining $\mathrm{J} \& \mathrm{~K}$ with anticipated movement in east-northeastward direction. An upper air cyclonic circulation lay over northwest Rajasthan and adjoining Pakistan, extending up to $0.9 \mathrm{~km}$ above sea level (figure 1a and b). The monsoon trough at mean sea level was passing through northwest Rajasthan, Madhya Pradesh and thence southeastwards on morning and persisted there till the evening with the mean position of monsoon trough running

Table 4. Synoptic situations recorded at 00 and 12 UTC during 15-17 June 2013 at Mukteshwar.

\begin{tabular}{|c|c|c|c|c|c|}
\hline Date & $\begin{array}{l}\text { Synoptic hrs } \\
\quad \text { in UTC }\end{array}$ & Cloud particulars & MSLP & $\mathrm{P} 24$ & $\begin{array}{l}\text { Wind direction/ } \\
\text { speed (knots) }\end{array}$ \\
\hline \multirow[t]{2}{*}{15 June, 203} & 3 & $\begin{array}{l}\text { Seven octa cloud cover with four octa } \\
\text { low clouds Sc and } \mathrm{Cu} \text { and five octa of } \\
\text { medium cloud Ac, base of low clouds } \\
\text { between } 200 \text { and } 299 \mathrm{M}\end{array}$ & - & 0 & $\mathrm{E} / 02$ \\
\hline & 12 & $\begin{array}{l}\text { Sky obscured with low cloud St base } \\
\text { of low clouds at } 49 \mathrm{M}\end{array}$ & - & 0.5 & $\mathrm{NE} / 02$ \\
\hline \multirow[t]{2}{*}{16 June, 2013} & 3 & $\begin{array}{l}\text { Sky obscured with low cloud St base of } \\
\text { low clouds at } 0-49 \mathrm{M}\end{array}$ & - & -2.8 & $\mathrm{NE} / 06$ \\
\hline & 12 & $\begin{array}{l}\text { Sky obscured with low cloud St base of } \\
\text { low clouds at } 0-49 \mathrm{M}\end{array}$ & - & -2.5 & $\mathrm{E} / 04$ \\
\hline \multirow[t]{2}{*}{17 June, 2013} & 3 & $\begin{array}{l}\text { Sky obscured with low cloud St base of } \\
\text { low clouds at } 0-49 \mathrm{M}\end{array}$ & - & -2 & $\mathrm{E} / 02$ \\
\hline & 12 & $\begin{array}{l}\text { Sky obscured with low cloud St base of } \\
\text { low cloud at } 0-49 \mathrm{M}\end{array}$ & - & -17 & $\mathrm{E} / 02$ \\
\hline
\end{tabular}

Table 5. Synoptic situations recorded at 00 and 12 UTC during 15-17 June 2013 at New Tehri.

\begin{tabular}{|c|c|c|c|c|c|}
\hline Date & $\begin{array}{l}\text { Synoptic hrs } \\
\text { in UTC }\end{array}$ & Cloud particulars & MSLP & P24 & $\begin{array}{c}\text { Wind direction/ } \\
\text { speed (knots) }\end{array}$ \\
\hline \multirow[t]{2}{*}{15 June, 203} & 3 & $\begin{array}{l}\text { Seven octa cloud cover with six octa low } \\
\text { clouds } \mathrm{St}, \mathrm{Sc} \text { and } \mathrm{Cb} \text { and five octa of } \\
\text { medium cloud of } \mathrm{Ac} \text {, base of low clouds } \\
\text { between } 50 \text { and } 99 \mathrm{M}\end{array}$ & - & 0 & $\mathrm{~W} / 02$ \\
\hline & 12 & $\begin{array}{l}\text { Seven octa cloud cover with four octa low } \\
\text { clouds Sc and five octa of medium cloud of Ac, } \\
\text { base of low clouds between } 100 \text { and } 199 \mathrm{M}\end{array}$ & - & 0.4 & $\mathrm{SE} / 01$ \\
\hline \multirow[t]{2}{*}{16 June, 2013} & 3 & $\begin{array}{l}\text { Seven octa cloud cover with five octa low clouds Sc } \\
\text { and } \mathrm{Cb} \text { and seven octa of medium cloud of } \\
\text { Ac and As, base of low clouds } \\
\text { between } 100 \text { and } 199 \mathrm{M}\end{array}$ & - & -2.6 & $\mathrm{~W} / 03$ \\
\hline & 12 & $\begin{array}{l}\text { Seven octa cloud cover with five octa low clouds Sc } \\
\text { and } \mathrm{Cb} \text { and five octa of medium cloud } \\
\text { of } \mathrm{Ac} \text {, base of low clouds } \\
\text { between } 100 \text { and } 199 \mathrm{M}\end{array}$ & - & -3.1 & SW/02 \\
\hline \multirow[t]{2}{*}{17 June, 2013} & 3 & $\begin{array}{l}\text { Seven octa cloud cover with five octa low clouds Sc } \\
\text { and } \mathrm{Cu} \text { and seven octa of medium cloud of } \\
\text { Ac and As, base of low clouds } \\
\text { between } 100 \text { and } 199 \mathrm{M}\end{array}$ & - & -2.6 & SW/01 \\
\hline & 12 & $\begin{array}{l}\text { Seven octa cloud cover with five octa low clouds St } \\
\text { and Sc and five octa of medium cloud of } \\
\text { Ac and As, base of low clouds } \\
\text { between } 50 \text { and } 99 \mathrm{M}\end{array}$ & - & -1.6 & $\mathrm{SE} / 01$ \\
\hline
\end{tabular}



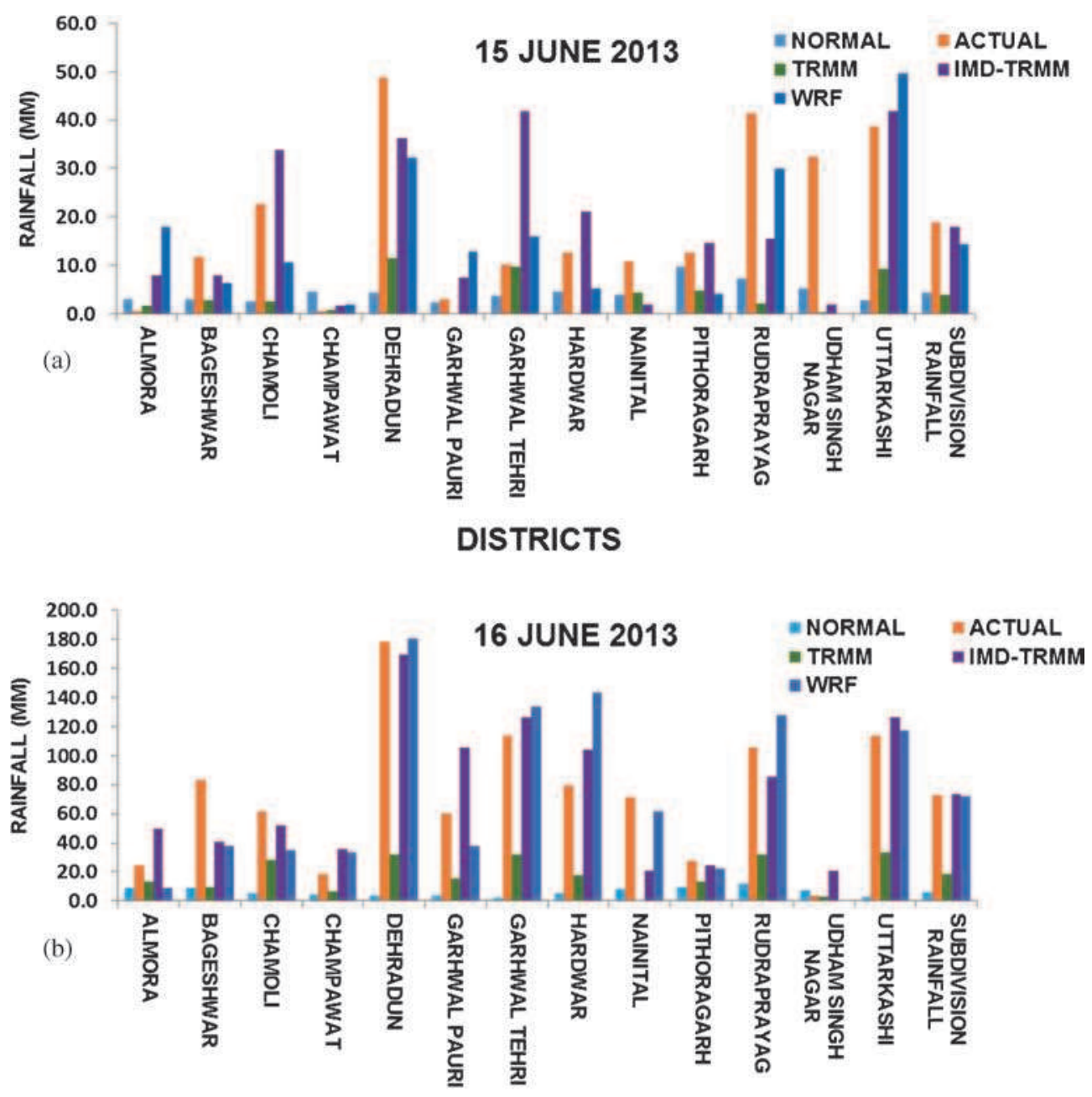

\section{DISTRICTS}

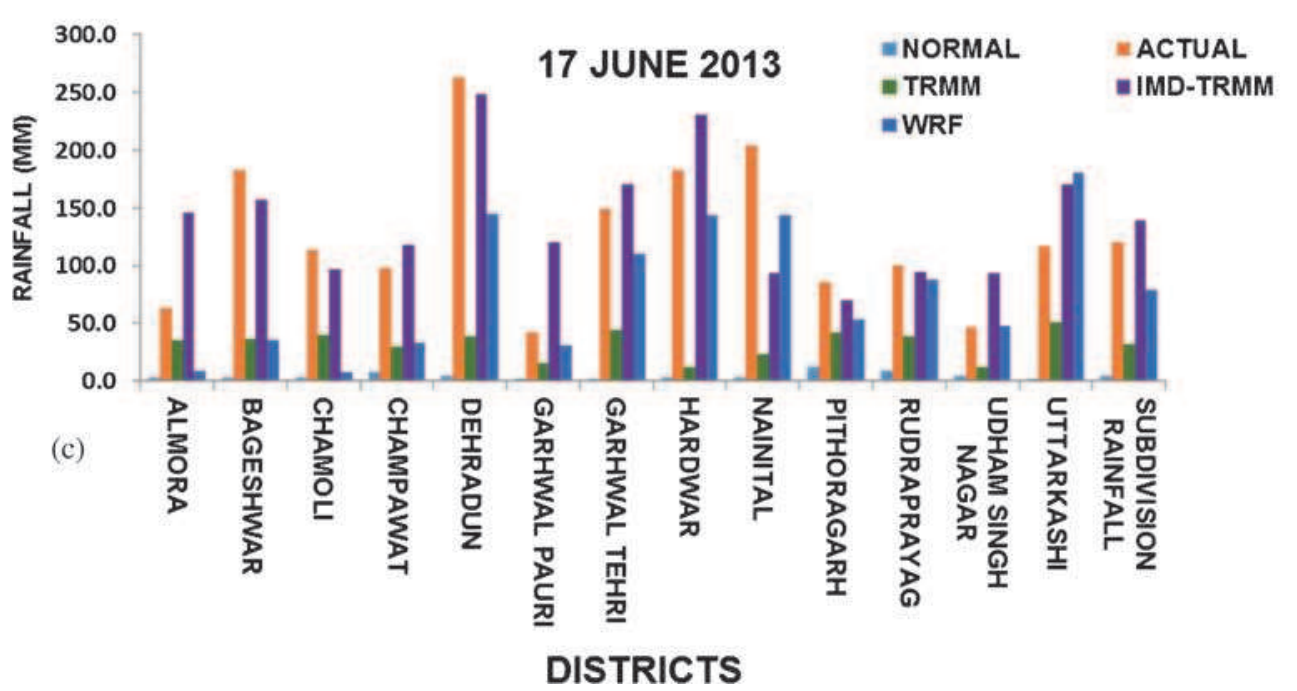

Figure 4. Comparison of rainfall distribution over different districts of Uttarakhand from normal, actual, TRMM, IMDTRMM and WRF model during (a) 15 June 2013, (b) 16 June 2013, and (c) 17 June 2013. 
through west Rajasthan, center of low pressure area lying over west Madhya Pradesh, Chhattisgarh and southeastwards with the advance of monsoon in Himachal Pradesh and Uttarakhand.

On 16 June 2013, the WD moved northeastward across the western Himalayan region. A trough existed in mid- and upper-tropospheric westerly. Low pressure area over west Madhya Pradesh and adjoining Chhattisgarh existed over west Madhya Pradesh and adjoining east Rajasthan on 16 June with upper air cyclonic circulation extending up to $7.6 \mathrm{~km}$ above sea level tilting southwestward with height (figure $2 \mathrm{a}$ and $\mathrm{b}$ ). Cyclonic circulation over northwest Rajasthan and adjoining Pakistan merged with the monsoon trough. The axis of the trough was passing through Jaisalmer, centre of low pressure area (LOPAR) and hence, seaward to head Bay of Bengal.
During 17 June 2013, the LOPAR over west Madhya Pradesh and adjoining east Rajasthan laid over northeast Rajasthan and adjoining Haryana with associated cyclonic circulation extending up to $3.6 \mathrm{~km}$ above sea level (figure $3 \mathrm{a}$ and $\mathrm{b}$ ). The monsoon trough passed through Phalodi, LOPAR, Agartala, Kanpur and thence southeastward. The details of synoptic situations recorded at 00 and 12 UTC at Dehradun (table 2), Pant Nagar (table 3), Mukteshwar (table 4) and New Tehri (table 5) during 15-17 June 2013 are presented.

The synoptic conditions of winds over 850 and $500 \mathrm{hPa}$ have also been described in detail by Dube et al. (2013). The $850 \mathrm{hPa}$ wind shows a low pressure system initially observed on 15 June near the east coast of India. It moved northwestwards from 16 to 18 of June. On 18 June, this system was located near western region of Uttar Pradesh
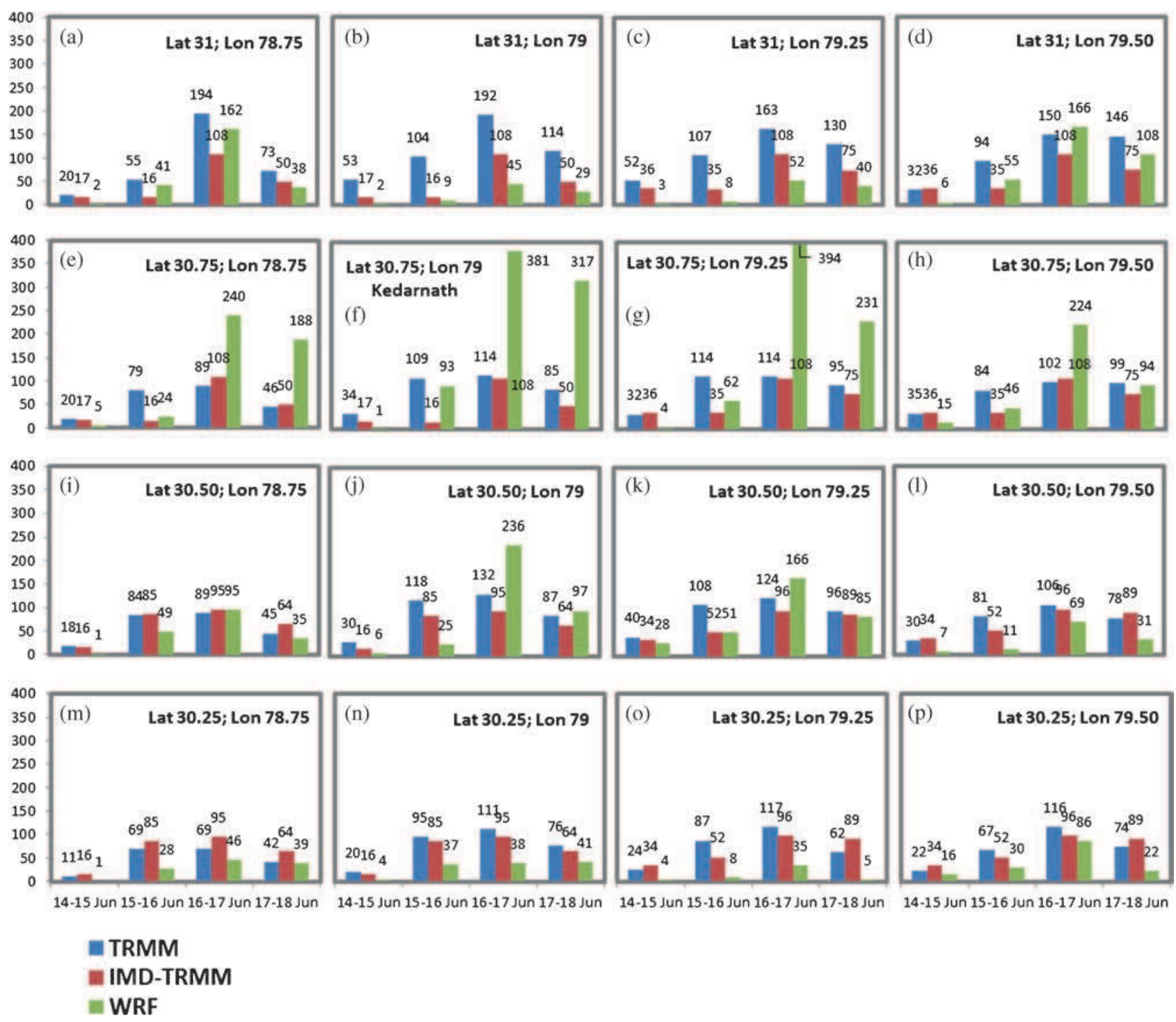

Figure 5. Twentyfour-hr accumulated rainfall from TRMM, IMD-TRMM merged data and WRF model simulation over different grid points surrounding the Kedarnath (f) during the period from 14-15 to 17-18 June 2013. 
and eastern parts of Haryana. The $500 \mathrm{hPa}$ wind from 15 to 18 June also showed the eastward movement of the WD in the form of a trough over north India.

\subsection{Numerical simulation of the event}

The WRF model is integrated at $3 \mathrm{~km}$ horizontal resolution as described in section 2 and the model simulated rainfall are presented in this section.
The estimated rainfall from the Tropical Rainfall Measurement Mission (TRMM) 3B42 satellite products (http://agdisc.gsfc.nasa.gov/Giovanni/ aovas/realtime.3B42RT.shtml) as well as the IMDTRMM merged data (Mitra et al. 2009) are also analyzed and compared with model simulation. Districts of Rudraprayag, Uttarkashi, Chamoli, Pauri and Tehri, Dehradun and adjoining districts received very heavy to exceptionally heavy rainfall from 15 to 17 June 2013, which was more than $200 \%$ of their normal rainfall. Figure 4 presents
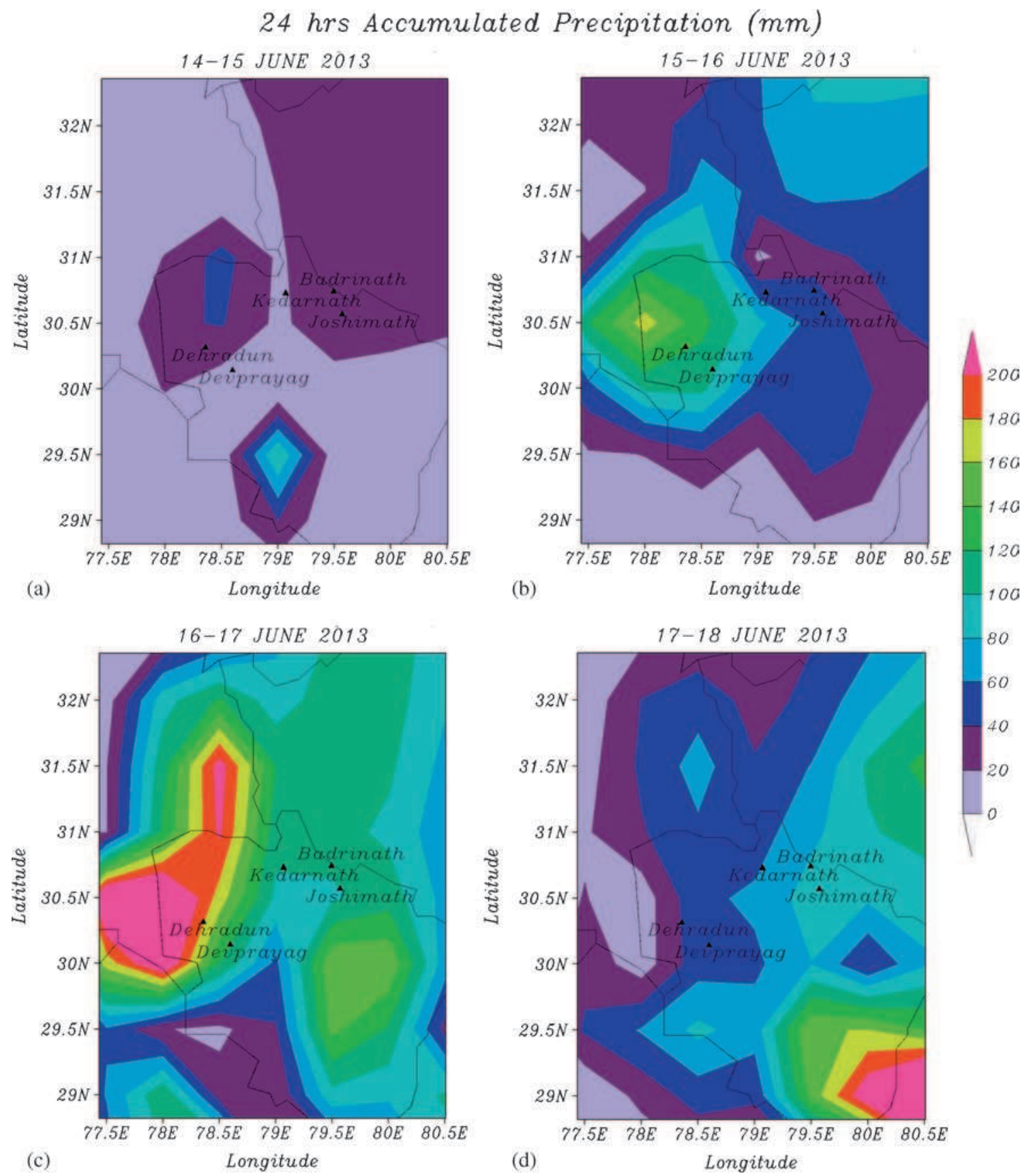

Figure 6. Spatial distribution of 24-hr accumulated rainfall based on IMD-TRMM merged precipitation for the period (a) 14-15 June 2013, (b) 15-16 June 2013, (c) 16-17 June 2013, and (d) 17-18 June 2013. 
the district-wise rainfall distribution and their departure from normal on 15-17 June 2013. It also demonstrates the comparison of rainfall estimated from TRMM, IMD-TRMM and WRF model simulated values. The WRF model has well simulated the rainfall distribution and reasonably matched with IMD-TRMM merged datasets. The TRMM data shows the underprediction of rainfall. On 15 June 2013, WRF model simulated rainfall matches well with the actual rainfall in most of the districts such as Bageshwar, Chamoli, Champawat, Dehradun, Rudraprayag, Uttarkashi, etc. The subdivisional rainfall on 15 June 2013 was $18.9 \mathrm{~cm}$ and it was $430 \%$ more than normal. The TRMM estimated rainfall was $3.8 \mathrm{~cm}$, however, WRF could simulate about $14.4 \mathrm{~cm}$ which is closer to the IMD-TRMM estimated rainfall of $18.0 \mathrm{~cm}$. In the same way, the district-wise rainfall is well simulated

\section{4 hrs Accumulated Precipitation $(\mathrm{mm})$}
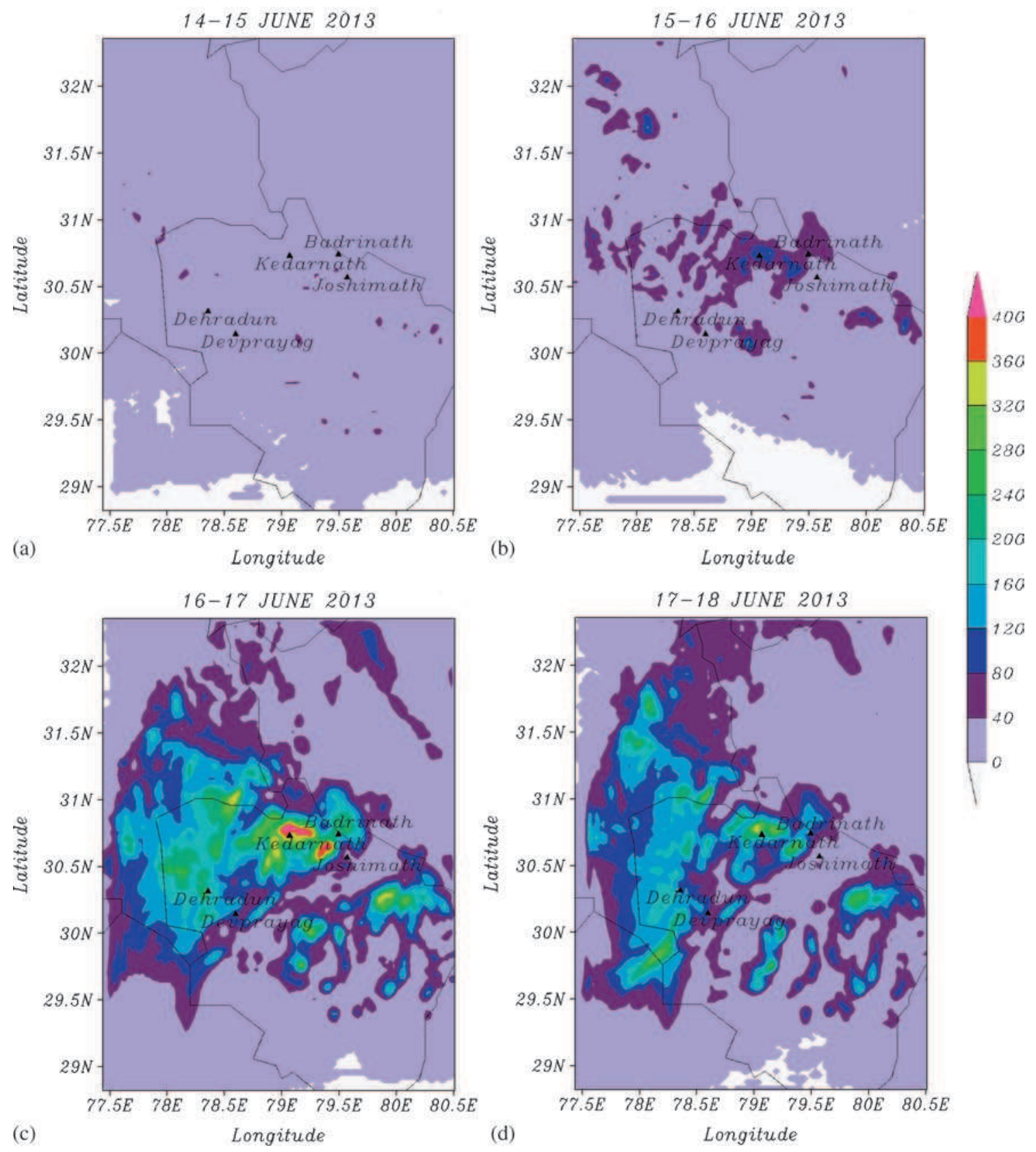

Figure 7. Twentyfour-hr accumulated precipitation as simulated by WRF model at $3 \mathrm{~km}$ horizontal resolution for (a) 14-15 June 2013, (b) 15-16 June 2013, (c) 16-17 June 2013, and (d) 17-18 June 2013. 
in the WRF model for both 16 and 17 June 2013. On 16 June, the sub-divisional rainfall was $72.7 \mathrm{~cm}$ and WRF could simulate about 72.2 $\mathrm{cm}$. The normal rainfall was $5.9 \mathrm{~cm}$ and TRMM estimated rainfall was $18.2 \mathrm{~cm}$. Similarly, the subdivisional rainfall on 17 June 2013 was $120.6 \mathrm{~cm}$ and WRF could simulate about $79 \mathrm{~cm}$ and TRMM estimated rainfall was $32.3 \mathrm{~cm}$. The normal rainfall was $4.3 \mathrm{~cm}$. This shows that the high resolution mesoscale model was able to capture the heavy rainfall reasonably well.

The meteorological station available near the Chorabari Glacier of Wadia Institute of Himalayan Geology (WIHG) recorded $325 \mathrm{~mm}$ rainfall at the base of the glacier in two days of 15 and 16 June 2013 (Dobhal et al. 2013). Twentyfour-hr accumulated rainfall based on TRMM and IMD-TRMM estimated precipitation and the WRF model simulation over different grid points surrounding the Kedarnath during the period from 14-15 June 2013 to 17-18 June 2013 have been depicted in figure 5 . Results show that grid point of TRMM nearer to the Kedarnath temple area (f) has captured 109 and $114 \mathrm{~mm}$ precipitation during $15-16$ and 1617 June 2013. However, the WRF model could simulate about $381 \mathrm{~mm}$ which is in good agreement with observed values of WIHG. The TRMM estimated rainfall is not in good agreement with the observed rainfall of $325 \mathrm{~mm}$ of Wadia Institute during the period. This may be attributed to very coarse resolution of the TRMM data. The sharp increase in the rainfall is neither estimated with TRMM, nor the IMD-TRMM, however, the WRF simulated result is reasonably matched with IMD-TRMM estimated rainfall. The spatial distribution of 24-hr accumulated precipitation from IMD-TRMM for the period from $14-15$ to $17-18$ June 2013 is depicted in figure 6. The spatial distribution of 24-hr accumulated precipitation as simulated by the WRF model at $3 \mathrm{~km}$ horizontal resolution is depicted in figure 7 . The rainfall simulated by WRF lies in the range of 320-400 $\mathrm{mm}$ over Kedarnath during the actual occurrence of the event, which is in reasonably good agreement with the observed value of WIHG (325 mm). This indicates that this catastrophic precipitation event which caused tremendous destruction and loss of life was well captured by WRF model. With a capability to forecast mountain weather six days in advance using this model, the predictability of such extreme events can be enhanced with a reasonably good level of accuracy. People can be forewarned about the impending disaster and consequent destruction and loss of precious lives can be effectively prevented.

More experiments need to be designed to study other parameters simulated by WRF such as winds, pressure and moisture, so as to understand the dynamics of the phenomena associated with this unprecedented heavy rainfall. Attempts are also being made here at SASE to restore the AWS of Kedarnath, so that collection of data for the region can be resumed and early warning of such extreme events could be issued to the users. Simulation of WRF model in further high resolution of $1 \times 1 \mathrm{~km}$ is also being attempted.

\section{Conclusions}

The State of Uttarakhand was severely affected by floods and landslides due to heavy rainfall in Kedarnath region on 16 June 2013. Results of WRF model run at SASE show that the rainfall associated with the event is well captured in the models. The district-wise and the sub-divisional rainfall is well simulated with WRF though the actual rainfall was $200 \%$ above the normal value. Experiments are being designed to study and understand the dynamics of the events in greater details by using other important parameters such as pressure, temperature, and relative humidity. Experiments are also being designed to run WRF model with a finer resolution up to $1 \mathrm{~km}$ along with various observational data assimilation techniques so as to simulate the vertical profile of the event and to study the thermodynamic properties of this localized phenomena.

\section{Acknowledgements}

This work is supported by the financial grant from Defence Research and Development Organization (DRDO) and Department of Science and Technology (DST), Govt. of India and is duly acknowledged. The authors are thankful to NCAR for providing the WRF model, NCEP for Final Analysis Data (FNL) and TRMM for precipitation data. The Meteorological Centre (India Meteorological Department), Chandigarh is duly acknowledged for providing synoptic information. Thanks are also due to Miss Usha Devi, JRF, Hazard Assessment and Forecasting Division (HAFD) for compiling model data. The authors are thankful to Dr. Asish Mitra, NCMRWF for providing IMD-TRMM merged rainfall data for this study.

\section{References}

Ashrit R 2010 A report on investigating the Leh cloudburst; NCMRWF report No. NMRF/RR/2010.

Dobhal D P, Gupta A K, Mehta M and Khandelwal D D 2013 Kedarnath disaster: Facts and plausible causes; Curr. Sci. 105 171-174. 
Dube A, Ashrit R, Ashish A, Sharma K, Iyengar G R, Rajagopal E N and Basu S 2013. Performance of NCMRWF forecast models in predicting the Uttarakhand heavy rainfall event during 17-18 June 2013; NCMRWF internal report No. NMRF/RR/08/2013.

Joseph S, Sahai A K, Sharmila S, Abhilash S, Borah N, Chattopadhyay R, Pillai P A, Rajeevan M and Kumar A 2014 North Indian heavy rainfall event during June 2013: Diagnostics and extended range prediction; Clim. Dyn., doi: $10.1007 / \mathrm{s} 00382-014-2291-5$.

Kanamitsu M 1989 Description of the NMC Global Data Assimilation and Forecast System; Wea. Forecasting 4 335342.

Mitra A K, Bohra A K, Rajeevan M N and Krishnamurti T N 2009 Daily Indian precipitation analyses formed from a merged of rain-gauge with TRMM TMPA satellitederived rainfall estimates; J. Meteor. Soc. Japan 87A 265-279.
Singh D, Horton D E, Tsiang M, Haugen M, Ashfaq M, Mei R, Rastogi D, Johnson N, Charland C, Rajaratnam B and Diffenbaugh N S 2014 Severe precipitation in northern India in June 2013: Causes, historical context and changes in probability; In: Explaining extreme events of 2013 from a climate perspective; Bull. Am. Meteorol. Soc. 95 S58-S61.

Sravana Kumar M, Shekhar M S, Rama Krishna S S V S, Bhutiyani M R and Ganju A 2012 Numerical simulation of cloud burst event on August 5, 2010, over Leh using WRF mesoscale model; Nat. Hazards 62 1261-1271.

Srinivasan J 2013 Predicting and managing extreme rainfall; Curr. Sci. 105 7-8.

Thayyen R J, Dimri A P, Kumar P and Agnihotri G 2013 Study of cloudburst and flash floods around Leh, India, during August 4-6, 2010; Nat. Hazards 65 21752204 . 